\title{
The Clinical Efficacy of Maizhiling Combined with Low Molecular Weight Heparin in the Treatment of Deep Vein Thrombosis after Spinal Cord Injury
}

\author{
XUEFANG MA*, XIAOFENG LIU, GAOWEI WANG, XIANG XIAAND XIAOBO YI
}

Department of Spine Surgery, Shenzhen Pingle Orthopedic Hospital (Shenzhen Pingshan District Traditional Chinese Medicine Hospital), Pingshan, Guangdong Province 518122, China

\section{Ma et al.: Clinical Efficacy of Maizhiling Combined with Low Molecular Weight Heparin}

\begin{abstract}
This research aims to discuss the clinical efficacy of Maizhiling combined with low molecular weight heparin calcium in the treatment of deep vein thrombosis after spinal cord injury, in the meantime to discuss the effects of the drug combination on coagulation function, hemodynamics and clinical safety. We chose 40 patients with deep vein thrombosis after spinal cord injury in our hospital as the study cohort divided them into control group $(n=20)$ and observation group $(n=20)$ randomly. The control group received low molecular weight heparin calcium subcutaneous injections while the observation group received low molecular weight heparin calcium intravenous infusion of low molecular weight heparin calcium and oral Maizhiling. Then make a contrast of the affected limbs detumescence time, lower limb circumference, coagulation parameters, overall response rate, incidence of complications and adverse drug reactions after treatment between both groups. After treatment, the observation group's swelling time and the average difference of lower limb circumference were significantly reduced $(\mathbf{p}<0.01)$, prothrombin time, activated partial thromboplastin time and D-dimer both were significantly lower $(p<0.01)$ and the clinical effective rate was higher $(\mathbf{p}<\mathbf{0 . 0 5})$. Both groups incidence of complications and adverse drug reactions have no significant difference $(\mathrm{p}>\mathbf{0 . 0 5})$. Low molecular weight heparin calcium combined with Maizhiling is effective on spinal cord injury deep vein thrombosis patients. The lower extremity swelling time is significantly shortened, the blood coagulation function and blood viscosity are improved, and the adverse drug incidence and complications are not increased. The combined use is used to treat patients with deep vein thrombosis. It is worth widely using in clinical practice.
\end{abstract}

Key words: Maizhiling, low molecular weight heparin calcium, spinal cord injury, deep vein thrombosis

Spinal cord injury is on the rise in China, with an estimated annual incidence of 14000 cases $^{[1]}$. Spinal cord injury is the most common in middle-aged men and traffic accidents are the most common cause ${ }^{[2]}$. The most common complications of spinal cord injury are Deep Vein Thrombosis (DVT) and pulmonary embolism ${ }^{[2,3]}$. DVT can easily cause tissue edema, varicose veins, lower limb dyskinesia and even serious complications such as pulmonary embolism caused by thrombosis, venous blood stasis and hypercoagulability, which are life-threatening ${ }^{[4]}$. The incidence of spinal cord injury complicated by DVT reported in the literature is relatively high, as high as $65 \%$ in some studies ${ }^{[5]}$. In one previous study of 94 spinal cord injury patients, it was found that most venous thromboembolism occurred within 3 mo after spinal cord injury. Although the risk of DVT decreases with the time of injury, it will never return to the baseline level[6].

Studies have reported that if DVT is not treated in time, it can lead to patients with large-scale pulmonary embolism and the incidence rate is $20 \%-30 \%{ }^{[7]}$. DVT treatment includes a lot of joint contents such as thrombolytic therapy, anticoagulation, Inferior Vena Cava (IVC) filter indwelling, mechanical thrombectomy, Traditional Chinese Medicine (TCM), acupoint compression and psychological intervention ${ }^{[8,9]}$. We should create individualized treatment plans in line with the patient's age, etiology, course of disease, thrombus classification etc., in clinic. For DVT, anticoagulation therapy has a better effect. Low Molecular Weight Heparin Calcium (LMWH-Ca) not only decrease activity of coagulation factor or blood viscosity but

*Address for correspondence

E-mail: mxuefeng@126.com 
also can remarkably relieve the hypercoagulable state. Maizhiling has effects on extending clotting time, inhibiting thrombosis and improving the patient's lower limbs microcirculation. Most spinal cord injury patients are in bed with hypercoagulability state or vascular injury caused by surgery and they belong to the high-risk group of DVT. There are some studies on LMWH-Ca or Maizhiling alone in the treatment of DVT, but there is still a lack of studies on combination therapy for patients with spinal cord injury and DVT inside and outside of China ${ }^{[10,11]}$. Therefore, we mainly discussed the clinical efficacy analysis of LMWH-Ca combined with Maizhiling in treatment of spinal cord injury patients with DVT, as well as the effects on lower limb circumference, coagulation function, clinical efficiency, complications and adverse reactions, then to guide our clinical therapy.

\section{MATERIALS AND METHODS}

\section{General information:}

We chose 40 inpatients with spinal cord injury complicated by DVT in our hospital from February 2016 to March 2021 as the study cohort. Divided them into treatment group and control group, each groups contained 20 patients. The general information of both groups is shown in Table 1. This study is approved from Medical Ethics Committee of our hospital.

Inclusion criteria-Patients who met the DVT diagnostic criteria proposed in "Guidelines for the diagnosis and treatment of DVT"[12,13] and patients in the acute phase of DVT were diagnosed by lower limb venography, color Doppler ultrasound and D-dimer; patients who were not allergic to the used drugs in this research; all of them obtained informed consent for treatment.

Exclusion criteria-Patients with bleeding; severe liver disease or renal dysfunction in children; patients received relevant antithrombotic therapy within 1 w; critically ill patients with mental illness before admission; patients with cognitive impairment.

\section{Methods:}

Both groups of patients received conventional treatment and nursing, and they were instructed to routinely press limbs to prevent thrombosis. We recommended a lowfat, high-vitamin and high-protein diet to make sure to defecate smoothly and prevent thrombosis or embolism from falling off.

Drug treatment: The control group was given subcutaneous injection of LMWH-Ca2500 International unit (IU) each time twice a day for $2 \mathrm{w}$; the observation group received the same LMWH-Ca dose and also Maizhiling (0.3 g; orally (po); twice a day (BID)) made by Cesra Arzneimittel GmbH \& Co. KG.

Observation indicators: Main outcome indicatorsObserve and record the swelling time of the two groups of patients; compare the calf and thigh diameters of both groups; $14 \mathrm{~d}$ after treatment, compare the treatment effects of both groups: Ineffective-vascular ultrasonography showed that the recanalization rate of popliteal and femoral veins was less than $40 \%$, there was no collateral circulation and there was no relief of swelling and pain on affected limbs. Improved-vascular ultrasound examination showed that the recanalization rate of popliteal and femoral veins was $40 \%-75 \%$, insufficient collateral circulation and relief of local swelling and pain of the limbs; Cure, complete reliefvascular ultrasound examination showed that the recanalization rate of popliteal vein and femoral vein was $76 \%-90 \%$, adequate collateral circulation and the swelling and pain symptoms were significantly relieved.

\section{Detection and comparison of the secondary results:}

Compared the coagulation function of the two groups: Fibrinogen (FIB), Prothrombin Time (PT), Activated Partial Thromboplastin Time (APTT) levels; compared D-dimer and deep vein color Doppler ultrasound of both groups lower limbs; comparison of complications during treatment, such as thrombocytopenia, hematuria, dyspnea, melena, bleeding gums, hemoptysis, epistaxis, etc. During the treatment, compare both group's adverse drug reactions such as nausea, rash, dizziness, vomiting, diarrhea and abdominal pain.

\section{Statistical methods:}

We adopt Statistical Package for the Social Sciences (SPSS) 20.0 to analyze the data, use $n \%$ to express technical data and use $\chi^{2}$ to test. Use mean \pm standard deviation to indicate measurement data that is accord with normal distribution and homogeneity of variance, compare both groups by independent sample $t$ test before and after treatment and within the same group comparison was expressed by paired $t$ test. Use median and interquartile range to show data that did not accord with normal distribution. The Wilcoxon test was used for group's comparison and the Wilcoxon signed rank test was used for comparison before and after treatment within the same group, $p<0.05$ was supported to possess statistical significance.

\section{RESULTS AND DISCUSSION}

General information of both groups was compared. 
There was no any significant differences between two groups in terms of age, gender, location of thrombus, type of thrombus formation, etc., and there was no statistical significance $(p>0.05)$. These two groups possessed comparability (Table 1 ).

Coagulation indexes and D-dimer between both groups after treatment were compared. There was no any significant differences in FIB, PT, APTT or D-dimer between both groups before cure $(p>0.05)$ and there was no statistical significance. There was no statistical difference between both groups before and after horizontal treatment; PT, FIB, APTT and D-dimer levels after cure in the control group were remarkably higher the other $(\mathrm{p}<0.05)$, with statistical significance (Table 2).

Various clinical symptom scores of both groups before and after treatment were compared. There was zero difference in various clinical symptoms scores (swelling of the affected limb, skin temperature) and circumference of the upper and lower legs before treatment for both groups $(\mathrm{p}>0.05)$, it has no statistical significance. Both group's clinical symptom scores decreased remarkably and the upper and lower legs circumference was significantly reduced. Make comparison of the same group before treatment, the differences had statistical significance $(\mathrm{p}<0.05)$. Various clinical symptoms scores and the upper and lower legs circumference were different between both groups after treatment and both of them had statistical significance $(\mathrm{p}<0.05)$ (Table 3$)$.

Overall response rate between both groups were compared. The observation group total remission rate remarkably exceeds the other $(\mathrm{p}<0.05)$ (Table 4$)$.

Complication rates of both groups were compared. The difference in the incidence of complications (hematuria, allergic reactions, thrombocytopenia, dyspnea) between both groups is of no statistically significance $(p>0.05)$ (Table 5).

Incidence of adverse drug reactions of both groups was compared. Within observation group, 6 cases $(30 \%)$ had adverse reactions, including 1 case of skin rash, 1 case of nausea and vomiting, 2 cases of abdominal pain and diarrhea and 2 cases of loss of appetite. Within control group, 4 cases $(20 \%)$ had adverse reactions, including 2 cases of skin rash, 1 case of nausea and vomiting, and 1 case of abdominal pain and diarrhea. Adverse drug reactions between both groups has no statistical difference $(p>0.05)$ (Table 6).

\section{TABLE 1: COMPARISON OF GENERAL INFORMATION OF BOTH GROUPS}

\begin{tabular}{lcccc}
\hline & $\begin{array}{c}\text { Observation group } \\
(\mathrm{n}=20)\end{array}$ & Control group $(\mathrm{n}=20)$ & $\mathrm{t} / \chi^{2}$ & $\mathrm{P}$ \\
\hline Age & $63.4 \pm 8.72$ & $62.9 \pm 8.75$ & 0.21 & 0.82 \\
Gender (female) & $12(60 \%)$ & $11(55 \%)$ & 0.10 & 0.74 \\
Location of thrombus & & & 0.44 & 0.50 \\
Left lower limb & $6(30 \%)$ & $8(40 \%)$ & & \\
Right lower limb & $14(70 \%)$ & $12(60 \%)$ & & \\
Type of thrombus & & & 0.9 & 0.34 \\
Intermediate type & $8(40 \%)$ & $11(55 \%)$ & 0.48 & 0.49 \\
Peripheral type & $7(35 \%)$ & $5(25 \%)$ & 0.14 & 0.71 \\
Mixed type & $5(25 \%)$ & $4(20 \%)$ & & \\
\hline
\end{tabular}

TABLE 2: COMPARISON OF COAGULATION INDEXES AND D-DIMER BETWEEN BOTH GROUPS AFTER TREATMENT

\begin{tabular}{lccccccccc}
\hline & \multirow{2}{*}{$\begin{array}{c}\text { The } \\
\text { Group }\end{array}$} & \multicolumn{2}{c}{ FIB $(\mathrm{g} / \mathrm{l})$} & \multicolumn{2}{c}{ PT $(\mathrm{s})$} & \multicolumn{2}{c}{ APTT $(\mathrm{s})$} & \multicolumn{2}{c}{ D-dimer } \\
\cline { 3 - 10 } & of case & $\begin{array}{c}\text { Before } \\
\text { cure }\end{array}$ & After cure & $\begin{array}{c}\text { Before } \\
\text { cure }\end{array}$ & After cure & $\begin{array}{c}\text { Before } \\
\text { cure }\end{array}$ & After cure & Before cure & After cure \\
\hline $\begin{array}{l}\text { Control } \\
\text { group }\end{array}$ & 20 & $3.68 \pm 0.48$ & $3.06 \pm 0.55$ & $11.6 \pm 2.94$ & $15 . .01 \pm 2.42$ & $32.35 \pm 4.79$ & $35.25 \pm 4.46$ & $143.9 \pm 12.65$ & $103.95 \pm 9.10$ \\
$\begin{array}{l}\text { Observation } \\
\text { group }\end{array}$ & 20 & $3.71 \pm 0.45$ & $3.45 \pm 0.50$ & $11.7 \pm 2.92$ & $13.6 \pm 2.76$ & $32.5 \pm 4.82$ & $32.4 \pm 4.24$ & $144.65 \pm 11.61$ & $131.8 \pm 11.0$ \\
$\mathrm{t}$ & & -0.20 & -2.46 & -0.10 & 2.39 & -0.29 & 2.07 & -0.19 & -8.73 \\
$\mathrm{p}$ & 0.83 & 0.02 & 0.97 & 0.02 & 0.76 & 0.04 & 0.85 & 0.000 \\
\hline Special Issue 6, 2021 & \multicolumn{7}{c}{ Indian Journal of Pharmaceutical Sciences } & & 126
\end{tabular}


TABLE 3: COMPARISON OF VARIOUS CLINICAL SYMPTOM SCORES OF BOTH GROUPS BEFORE AND AFTER TREATMENT

\begin{tabular}{|c|c|c|c|c|c|}
\hline & & $\begin{array}{l}\text { Observation group } \\
\qquad(n=20)\end{array}$ & $\begin{array}{l}\text { Control group } \\
(n=20)\end{array}$ & $\mathrm{t}$ & $\mathrm{p}$ \\
\hline \multirow[t]{2}{*}{ Swelling } & Before cure & $2.71 \pm 0.47$ & $2.72 \pm 0.52$ & -0.06 & 0.94 \\
\hline & After cure & $0.95 \pm 0.46$ & $1.57 \pm 0.46$ & -4.26 & 0.001 \\
\hline \multirow[t]{2}{*}{ Skin temperature } & Before cure & $2.65 \pm 0.48$ & $2.61 \pm 0.57$ & 0.24 & 0.8 \\
\hline & After cure & $1.06 \pm 0.24$ & $1.76 \pm 0.92$ & -6.31 & 0.000 \\
\hline \multirow[t]{2}{*}{ Swelling time } & Before cure & $2.94 \pm 0.52$ & $3.04 \pm 0.50$ & -0.43 & 0.66 \\
\hline & After cure & $0.98 \pm 0.24$ & $1.42 \pm 0.54$ & -3.23 & 0.003 \\
\hline \multirow[t]{2}{*}{$\begin{array}{l}\text { Thigh } \\
\text { circumference }\end{array}$} & Before cure & $55.6 \pm 10.9$ & $54.75 \pm 9.58$ & 0.26 & 0.79 \\
\hline & After cure & $45.1 \pm 6.88$ & $50.1 \pm 7.11$ & -2.26 & 0.00 \\
\hline \multirow[t]{2}{*}{ Calf circumference } & Before cure & $42.16 \pm 4.65$ & $43.26 \pm 3.98$ & -0.80 & 0.43 \\
\hline & After cure & $32.20 \pm 7.20$ & $38.55 \pm 8.13$ & -2.59 & 0.01 \\
\hline
\end{tabular}

TABLE 4: COMPARISON OF THE OVERALL RESPONSE RATE BETWEEN THE TWO GROUPS

\begin{tabular}{|c|c|c|c|c|}
\hline & Apparent effect & Effective rate & Inefficiency rate & Total effective rate \\
\hline Observation group & $11(55 \%)$ & $7(35 \%)$ & $2(10 \%)$ & $18(90 \%)$ \\
\hline Control group & $8(40 \%)$ & $4(20 \%)$ & $8(40 \%)$ & $12(60 \%)$ \\
\hline$\chi^{2}$ & & & & 4.80 \\
\hline $\mathrm{p}$ & & & & 0.03 \\
\hline
\end{tabular}

TABLE 5: COMPARISON OF THE INCIDENCE OF COMPLICATIONS BETWEEN BOTH GROUPS

\begin{tabular}{|c|c|c|c|c|c|}
\hline & Hematuria & Allergic reactions & Thrombocytopenia & Dyspnea & Total \\
\hline Observation group & $1(5 \%)$ & $1(5 \%)$ & $2(10 \%)$ & $0(0 \%)$ & $4(20 \%)$ \\
\hline Control group & 1 (5 \%) & $2(10 \%)$ & $1(5 \%)$ & 1 (5 \%) & $5(25 \%)$ \\
\hline$\chi^{2}$ & & & & 4 & 0.14 \\
\hline $\mathrm{p}$ & & & & & 0.75 \\
\hline
\end{tabular}

TABLE 6: COMPARISON OF THE INCIDENCE OF ADVERSE DRUG REACTIONS BETWEEN BOTH GROUPS

\begin{tabular}{|c|c|c|c|c|c|}
\hline & $\begin{array}{c}\text { Nausea and } \\
\text { vomiting }\end{array}$ & $\begin{array}{l}\text { Abdominal pain } \\
\text { and diarrhea }\end{array}$ & Skin rash & Loss of appetite & $\begin{array}{l}\text { Total adverse } \\
\text { reaction rate }\end{array}$ \\
\hline Observation group & $1(\%)$ & $2(\%)$ & $1(\%)$ & $2(\%)$ & $6(30 \%)$ \\
\hline Control group & $1(\%)$ & $1(\%)$ & $2(\%)$ & $0(0 \%)$ & $4(20 \%)$ \\
\hline$\chi^{2}$ & & & & & 0.53 \\
\hline $\mathrm{p}$ & & & & & 0.46 \\
\hline
\end{tabular}

DVT is a common but preventable complication of hospitalized patients with spinal cord injury. If effective preventive measures are not taken, nearly $60 \%$ of patients with spinal cord injury will be complicated by DVT. However, the timing and drugs of anticoagulant thrombolytic therapy determine the prognosis of $\mathrm{DVT}^{[14]}$. A total of 96 patients with malignant tumor complicated with DVT were included in the study by Chen et al. ${ }^{[15]}$. Treat the control group with LMWH-Ca and treat the observation group in the same way, then with another Ligustrazine hydrochloride. The results proved that both groups lower limbs swelling went down varying degrees after treatment, but combined drugs application has a better influence on improving DVT, thus it has more superiority. This study attempts to estimate the clinical efficacy, safety and clinical application value of LMWH-Ca combined with Maizhiling in DVT treatment after spinal cord injury.

The main ingredient of Aescuven Forte tablets is aescin $^{[16]}$. Previous studies have shown that aescin 
in patients treatment with DVT is mainly to improve the blood circulation of the lower extremities and reduce edema and pain ${ }^{[17]}$. Wang et al. ${ }^{[18]}$ studied 40 patients with Chronic Venous Insufficiency (CVI) of lower extremities in Peking Union Medical College Hospital and divided them into two groups which are observation group $(n=23)$ and control group $(n=17)$ by random. Treat control group with elastic stockings and observation group with Maizhiling. The experiment results showed that the improvement of Transcutaneous Oxygen $\left(\mathrm{TcPO}_{2}\right)$, skin temperature and temperaturecontrolled blood flow in the lower extremity circulation in observation group was greater than the other. It shows that Maizhiling can significantly improve the blood circulation and coagulation function of the lower branch of the patient. In our study, patients in the observation group received LMWH-Ca combined with Maizhiling, the observation group clinical effective rate was significantly higher than the other compared with patients who used LMWH-Ca alone. Both groups incidence of complications have no difference which indicates that LMWH-Ca combined with Maizhiling is more effective in clinic and safer in DVT treatment with spinal cord injury.

APTT and PT, as indicators to reflect endogenous and exogenous coagulation pathways level and activity, have been widely used to determine the coagulation function ${ }^{[19]}$. PT mainly reflects its own ability of organizing coagulation factors, for example, coagulation factors I, II, V, VII and X. However, APTT mainly reflects coagulation factors levels such as VIII, IX, XI, XII in the blood. Platelets (PLT) can accumulate in the bleeding site and promote hemostasis. The activated PLT has a good effect on coagulation, so does its cleavage products. FIB can adjust plasma viscosity from endogenous and exogenous coagulation mechanisms ${ }^{[20]}$. In our study, compared with LMWH$\mathrm{Ca}$ alone, the treatment effect of patients receiving LMWH-Ca with Maizhiling was significantly better and the improvement of blood coagulation indexes (PT, APTT) was remarkably better than the other, and the results have no divergence with the results of similar studies $^{[21]}$. In addition, contrast control group, the circumference of the thigh and calf in the observation group was significantly smaller, and the swelling time of the calf was also shorter. It shows LMWH-Ca joint Maizhiling has better effect on DVT patients improving coagulation function and inhibiting thrombosis contrast LMWH-Ca alone. In addition, both groups are of no differences in total incidence of adverse drug reactions, indicating that Maizhiling enriching is safe and it will not enhance the side effects of the drug.

This study also has certain limitations. Because 40 samples of our study are small and there are individual differences among patients, the test results are not very convincing. In the future, it is necessary to design scientific and rigorous large-sample randomized controlled experiments. Moreover, we did not follow up patients with recurrent DVT after discharge from the hospital. Future studies also need to compare the clinical efficacy of the combination of these two drugs for longterm recurrence of DVT patients. In short, LMWH$\mathrm{Ca}$ combined with Maizhiling has effect on treating spinal cord injury DVT patients, significantly shorten the lower limbs swelling time, improve coagulation function and blood viscosity, and the combined use of treatment of DVT is worthy of clinical promotion.

\section{Conflict of interests:}

The authors declared no conflict of interest.

\section{REFERENCES}

1. Yu X, Liu W, Zhang HW. Analysis of related factors of deep venous thrombosis after spinal cord injury. Zhongguo $\mathrm{Gu}$ Shang 2020;33(2):140-3.

2. Mengi A, Ilhan I. An unexpected event after deep vein thrombosis in spinal cord injury: Ruptured Baker's cyst. J Spinal Cord Med 2020:1-4.

3. Nanclares BV, Padilla-Zambrano HS, El-Menyar A, MoscoteSalazar LR, Galwankar S, Pal R, et al. WACEM consensus paper on deep venous thrombosis after traumatic spinal cord injury. J Emerg Trauma Shock 2019;12(2):150.

4. diGiorgio AM, Tsolinas R, Alazzeh M, Haefeli J, Talbott JF, Ferguson AR, et al. Safety and effectiveness of early chemical deep venous thrombosis prophylaxis after spinal cord injury: Pilot prospective data. Neurosurg Focus 2017;43(5):E21.

5. Cheng X, Zhang L, Xie NC, Xu HL, Lian YJ. Association between small-intestinal bacterial overgrowth and deep vein thrombosis in patients with spinal cord injuries. J Thromb Haemost 2017;15(2):304-11.

6. Wu B, Luo S. Progress in the treatment of deep venous thrombosis of lower extremity. Youjiang Med J 2021;49(3):2336.

7. Ahlquist S, Park HY, Kelley B, Holly L, Shamie AN, Park DY. Venous thromboembolism chemoprophylaxis within 24 hours of surgery for spinal cord injury: Is it safe and effective? Neurospine 2020;17(2):407-16.

8. Adedigba JA, Oremakinde AA, Huang B, Maulucci CM, Malomo AO, Shokunbi TM, et al. Preliminary findings after non-operative management of traumatic cervical spinal cord injury on a background of degenerative disc disease: Providing optimum patient care and costs saving in a Nigerian setting. World Neurosurg 2020;142:246-54.

9. Mackiewicz-Milewska M, Cisowska-Adamiak M, Pyskir J, Świątkiewicz I. Usefulness of D-dimer and ultrasonography screening for detecting deep vein thrombosis in patients with spinal cord injury undergoing rehabilitation. J Clin Med 2021;10(4):689. 
10. Moore RM, Rimler J, Smith BR, Wirth GA, Paydar KZ. Venous thromboembolism: A comparison of chronic spinal cord injury and general surgery patients in a metropolitan veterans affairs hospital. Plast Reconstr Surg 2016;138(5):908e-14e.

11. Arnold PM, Harrop JS, Merli G, Tetreault LG, Kwon BK, Casha S, et al. Efficacy, safety, and timing of anticoagulant thromboprophylaxis for the prevention of venous thromboembolism in patients with acute spinal cord injury: A systematic review. Global Spine J 2017;7(3):138S-50S.

12. JCS joint working group. Guidelines for the diagnosis, treatment and prevention of pulmonary thromboembolism and deep vein thrombosis (JCS 2009)-Digest Version. Circ J 2011;75(5):1258-81.

13. Min SK, Kim YH, Joh JH, Kang JM, Park UJ, Kim HK, et al. Diagnosis and treatment of lower extremity deep vein thrombosis: Korean practice guidelines. Vasc Specialist Int 2016;32(3):77-104.

14. Piran S, Schulman S. Thromboprophylaxis in patients with acute spinal cord injury: A narrative review. Semin Thromb Hemost 2019;45(2):150-6.

15. Chen L, Jia YJ. Clinical observation of ligustrazine hydrochloride combined with low-dose low molecular weight heparin calcium in the treatment of malignant tumor complicated with lower extremity deep venous thrombosis. Shaanxi J Tradit Chin Med 2015;2:176-7.

16. Zheng M, Zhang FT, Wei Q. Clinical study of Maizhiling on lower extremity arterial ischemia-reperfusion injury. World Latest Med Inf 2020;89(20).
17. Wang QS, Jiang Y, Chen HT, Wang YL, Zhou B, Dai B, et al. Intervention effect of modified Dahuang Zhechong granule on epididymal morphological changes in experimental varicocele rats. Zhonghua Nan Ke Xue 2018;24(3):241-6.

18. Wang W, Wu L, Nie H, Liao PZ, Li FD, Liu D, et al. Effects of Aescuven forte on microcirculation for the treatment of chronic venous insufficiency. Chin J Mult Organ Dis Elderly 2018;17(7):486-90.

19. Harrold IM, Oladipo O. Elevated PT and aPTT. Clin Chem 2018;64(12):1790-1.

20. Zhang L, Ye J, Luo Q, Kuang M, Mao M, Dai S, et al. Prediction of poor outcomes in patients with colorectal cancer: Elevated preoperative prothrombin time (PT) and Activated Partial Thromboplastin Time (APTT). Cancer Manag Res 2020;12:5373.

21. Chandler E, Kakkar N, Kaur R. Comparison of rapid centrifugation technique with conventional centrifugation for prothrombin time (PT) and Activated Partial Thromboplastin Time (APTT) testing. Indian J Hematol Blood Transfus 2019;35(1):161-6.

This is an open access article distributed under the terms of the Creative Commons Attribution-NonCommercial-ShareAlike 3.0 License, which allows others to remix, tweak, and build upon the work non-commercially, as long as the author is credited and the new creations are licensed under the identical terms

This article was originally published in a special issue, "Novel Therapeutic Approaches in Biomedicine and Pharmaceutical Sciences" Indian J Pharm Sci 2021:83(6) Spl Issue “124-129" 